\title{
EMPIRICAL EQUATION OF LIQUEFACTION STRENGTH CURVE FOR SANDY SOILS
}

\author{
Takeko MIKAMI $^{1}$, Nozomu YOSHIDA ${ }^{2}$ and Kenji HARADA ${ }^{3}$ \\ ${ }^{1}$ Senior Chief Researcher, Technical Research Institute, Maeda Corporation, \\ Tokyo, Japan, mikami.take@jcity.maeda.co.jp \\ ${ }^{2}$ Member of JAEE, Professor, Dept. of Civil and Environmental Engineering, \\ Tohoku-Gakuin University, Tagajo, Japan, yoshidan@mail.tohoku-gakuin.ac.jp \\ ${ }^{3}$ Member of JAEE, Senior Manager, Geo-technical Division, Fudo Tetra Corporation, \\ Tokyo, Japan, kenji.harada@fudotetra.co.jp
}

\begin{abstract}
Empirical equations of liquefaction strength curve, which is applicable in wide range of number of cycles causing liquefaction and variety of sandy soil, are proposed for the effective stress analysis. Past similar researches have several disadvantages from the practical point of view; soil classification is not considered and applicable range is limited to small number of cycles or uncertain. In our research, many test results on undisturbed samples which include variety of soil classification and with number of cycles causing liquefaction larger than 100 are collected. About 200 test results are classified based on the geological age and the fines content. Considering the engineering practice, equations predicting $R_{\mathrm{L} 5}$ and $R_{\mathrm{L} 100}$ from $R_{\mathrm{L} 20}$ is proposed by classifying the geological age (Bs + As and Ds). Finally, a smooth equation is proposed for liquefaction strength curve which covers number of cycles causing liquefaction between 5 and 100 .
\end{abstract}

Key Words: Liquefaction strength curve, Geological age, Fine fraction content, Empirical equation

\section{INTRODUCTION}

An effective stress seismic response analysis has become to be frequently used in order to evaluate liquefaction behaviors of sandy ground during earthquakes. In this analysis, parameters of constitutive models must be evaluated so that liquefaction strength agrees with liquefaction curve (relationships between shear stress ratio amplitude and number of cycles causing liquefaction) at minimum. Here, the liquefaction strength curve is obtained by a cyclic shear test on the in-situ sampled test specimen. In the engineering practice, however, this test is sometimes not conducted because of several reasons such as cost etc. In this case, the liquefaction strength curve is evaluated based on empirical equations, and liquefaction strength shown in the design specification is frequently used for this purpose 
However, design specifications do not specify the liquefaction strength curve but specify the liquefaction strength at a particular number of cycles. For example, Design Specification for Road Bridge $^{1)}$ specifies the liquefaction strength at 20 cycles of loading, and Recommendations for Design of Building Foundations ${ }^{2)}$ specifies the one at 15 cycle of loading. This paper presents a method to develop liquefaction strength curves from the liquefaction strength at particular number of cycles obtained by design specifications or empirical equations.

Empirical equations of the liquefaction strength curve have been proposed in the past; representative ones are summarized in Table 1 based on the author's investigation. Tatsuoka et al. ${ }^{3)}$ proposed relationships between $\log R$ and $\log N_{c}$, where $R$ denotes liquefaction strength ratio and $N_{c}$ denotes number of cycles causing liquefaction. Since the coefficient of the slope is expressed as a function with respect to the double amplitude axial strain $D A$, liquefaction strength curve can be obtained by specifying a point on the curve. Looking at the original test data, the proposed equation seems to be applicable with number of cycles $N_{c}$ about 20 or less. It is also noted that density and/or grain size distribution are not considered. Kokusho et al. ${ }^{4)}$ expressed the liquefaction strength curve by two piecewise linear relationships between $\log R$ and $\log N_{\mathrm{c}}$ and pointed out that the slope depends on a relative density. They did not propose an empirical equation possibly because number of test specimens is not sufficient Azuma et al. ${ }^{5}$ proposed linear relationships between $R$ and $\log N_{c}$ and expressed coefficient of the slope as a function with respect to the relative density. Since the proposed equation is based on the Toyoura sand, applicability to other soils is uncertain. Yasu et al. ${ }^{6}$ ) added one more parameters to the proposed equation by Azuma et $\mathrm{al}^{5}$. In addition, they showed relationships of parameters $b$ and $c$ in Table 1 and $N_{1}$ (effective SPT- $N$ value considering the effective confining pressure; see Eq. (1) later for definition). They also expressed the new parameter as a function with respect to the geological age. Since frozen samples are used in their research, soils with large fines content are not included. In addition, relative density is considered but effect of the grain size characteristics is not considered.

As discussed, past researches used reconstituted specimens or particular soils for formulating the liquefaction strength curve. Therefore, applicability of the equations to practical problems is limited or uncertain. In addition, other problem arises as shown in the following in the engineering practice.

Liquefaction of silty sand with very large fines content or large plasticity index occurred in the past

Table 1. Empirical equations of liquefaction strength curve in past researches

\begin{tabular}{|c|l|l|l|}
\hline Equation & \multicolumn{1}{|c|}{ Author (s) } & \multicolumn{1}{|c|}{ Sampling } & $\begin{array}{l}\text { Samples. (parenthesis denotes } \\
\text { total number of data sets) }\end{array}$ \\
\hline \hline$R=R_{L 20}\left(\frac{N_{c}}{20}\right)^{a}$ & Tatsuoka et al. ${ }^{3)}$ & Tube sample & Fill and Holocene sand (73) \\
\hline- & Kokusho et al. ${ }^{4)}$ & Reconstituted sample & Holocene sand (1) \\
\hline$R=\frac{b}{N_{c}}+c$ & Azuma et al. ${ }^{5}$ & Reconstituted sample & $\begin{array}{l}\text { Toyoura sand (5 different } \\
\text { relative density) }\end{array}$ \\
\hline$R=\frac{b}{N_{c}^{e}}+c$ & Yasu et al.6) & Frozen sample & $\begin{array}{l}\text { Holocene sand (15) and } \\
\text { Pleistocene sand (14) }\end{array}$ \\
\hline$R_{L 5}=e R_{L 20}^{a}$ & Mikami et al. $\left.{ }^{8}\right)$ & Tube sample & $\begin{array}{l}\text { Fill (67), Holocene sand (198), } \\
\text { and Pleistocene sand (37) }\end{array}$ \\
\hline
\end{tabular}

Note: $a, b, c$, and $d$ are parameters. 
such as at Takenouchi industrial complex during the 2000 Tottoriken-seibu earthquake and in the Urauasu city during the 2011 Tohoku earthquake. These silty sands were out of consideration in the conventional design specifications; empirical equations that treat variety of soils are desired. Duration of the 2011 Tohoku earthquake was very long because fault length extends for about $500 \mathrm{~km}$, which is supposed to result in the liquefaction in large extent because number of effective cycles is large. In Japan, large earthquakes similar to 2011 earthquake, named the Tokai, Tonankai and Nankai earthquakes, are expected in the western area in near future. Number of effective cycles under these earthquakes is expected to be several tens ${ }^{7}$. Therefore, empirical equations that consider large number of cycles are also requested.

The authors collected about 300 liquefaction strength test results and developed empirical equations $^{8)}$ that can evaluate liquefaction strength $R_{L 5}$ from $R_{L 20}$, where $R_{L k}$ denotes liquefaction strength when $N_{c}=k$, and $k$ is either 5,20, or 100. This research focused on the behavior under $N_{c}=20$ or less. Considering the above requirement, data that included large cycles of loading are retrieved from the collected data and in order to develop an empirical equation applicable at $N_{c}=100$.

\section{DATA SETS}

In order to investigate the behavior in long duration earthquake or large number of loading cycles, totally 193 test data which include $N_{c}$ greater than 100 are selected among the 300 liquefaction strength test results that the authors collected ${ }^{8)}$.

Table $2^{9)}$ shows locations of sampled places. Sampled sites are located at all over Japan although sites in the Kanto district are somewhat larger than other districts. All the samples were sampled by means of a tube sampler. Samples with small fines contents are frozen at the site and carried to the laboratory so as to avoid disturbance during travelling. Characteristics of samples are shown in Figure 1. Specimens are mainly fill (Bs) and Holocene sand (As), and some Diluvial sands are included. Effective SPT- $N$ value $N_{1}$ spread widely from loose sand $\left(N_{1} \leq 10\right)$ to dense sand $\left(N_{1}>20\right)$. Samples with large fines content are included. In other words, variety of sands is used in the data sets.

Liquefaction strength test were based on the recommended method by the Japanese Geotechnical Society (JGS0541-2009) for the tri-axial test equipment. At first, samples were saturated so that the pore pressure parameter $B$ ( $B$ value) is greater than $95 \%$. Then they were isotopically consolidated to the effective overburden stress $\sigma_{c}^{\prime}$. Cyclic loading were carried by applying the constant amplitude shear stress as a $0.5 \mathrm{~Hz}$ sinusoidal wave up to the double amplitude $D A$ exceeds $10 \%$. Three to five

Table2. Locations of sampled sites ${ }^{9)}$

\begin{tabular}{|l|c|c|}
\hline \multicolumn{1}{|c|}{ District } & $\begin{array}{c}\text { No. of } \\
\text { sampling points }\end{array}$ & $\begin{array}{c}\text { No. of } \\
\text { samples }\end{array}$ \\
\hline Hokkaido & 3 & 6 \\
\hline Tohoku & 9 & 25 \\
\hline Kanto & 30 & 68 \\
\hline Hokuriku & 13 & 35 \\
\hline Tokai & 10 & 29 \\
\hline Kinki & 6 & 8 \\
\hline Chugoku \& Shikoku & 7 & 15 \\
\hline Kyushu & 4 & 8 \\
\hline Total & 82 & 194 \\
\hline
\end{tabular}

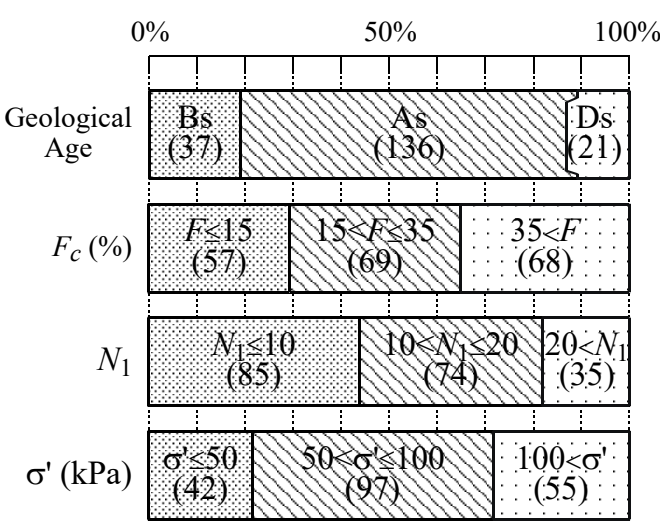

Figure 1. Characteristics of specimen ${ }^{9)}$ 
specimens were used for one test. Double amplitude axial strain $D A=5 \%$ is used to define onset of liquefaction in this research, which is usually used criteria in Japan. Test results are plotted as the cyclic shear stress ratio $R\left(=\sigma_{\mathrm{d}}^{\prime} /\left(2 \sigma_{c}^{\prime}\right)\right)$ versus number of cycles causing liquefaction $N_{c}$ relationships. Then $R$ at $N_{c}=5,20$, and 100 are read from the liquefaction strength curve. Here, in order to avoid human error, smoothing of the liquefaction strength curve is made by the same operator. If data point scatters, average curve is interpolated, and data that looks extraordinary because of pre-deformation before the test are eliminated.

\section{PATTERN OF LIQUEFACTION STRENGTH CURVE}

Relationships between $R_{L 20}$ and corrected SPT- $N$ value $N_{a}$ (SPT- $N$ value considering the effect of both effective confining pressure and fines content) is shown in shown in Figures 2 and 3, considering the geological age dependence and fines content dependence. Liquefaction strength by the Design Specification of Road Bridge ${ }^{2)}$ (Road Bridge equation, in the followings), shown in Eq. (1), is also written in the figure.

$$
R_{L 20}= \begin{cases}0.0882 \sqrt{N_{a} / 17} & \left(N_{a}<14\right) \\ 0.0882 \sqrt{N_{a} / 17}+1.6 \times 10^{-6} \cdot\left(N_{a}-14\right)^{4.5} & \left(14 \leq N_{a}\right)\end{cases}
$$

where

$$
\begin{aligned}
& N_{a}=c_{1} N_{1}+c_{2} \\
& c_{1}= \begin{cases}1 & \left(0 \% \leq F_{c}<10 \%\right) \\
\left(F_{c}+40\right) / 50 & \left(10 \% \leq F_{c}<60 \%\right) \\
F_{c} / 20-1 & \left(60 \% \leq F_{c}\right)\end{cases} \\
& c_{2}= \begin{cases}0 & \left(0 \% \leq F_{c}<10 \%\right) \\
\left(F_{c}-10\right) / 18 & \left(10 \% \leq F_{c}\right)\end{cases}
\end{aligned}
$$

There are significant scatter in all figures. When focusing on the geological age, data points scatter at both side of the Road Bridge equation for Bs in Figure 2(a). Data point moves downward in general as geological age becomes older, and, as can be seen in Figure 2(c) almost all data points lie under the Road Bridge equation. At the same time, however, as $\mathrm{N}$-values of the soils in older geological age are larger, liquefaction strength of the soil in the older geological age is larger than that in the younger geological age in an average. These aging effects of the liquefaction strength are harmonic with the past research ${ }^{10)}$. On the other hand, as shown in Figure 3, number of data points that locate under the Road Bridge equation becomes smaller as the fines content increases.

The Road Bridge equation was developed based on the liquefaction strength test by frozen samples ${ }^{11)}$, and test data in this research scatters in both side of the Road Bridge equation when $N_{1}$ value is less than 30. It is well known that liquefaction strengths of the tube sample Specimen used in this research is generally smaller than the liquefaction strength by frozen samples as shown in ref. 12 as an example. Judging from these factors, data used in this research are harmonic with the past researches.

Figure 4 shows liquefaction strength of Holocene sand (As) by classifying fines content $F_{c}$ and $N_{1}$, as an example. Here effective SPT- $N$ value, $N_{1}$, is evaluated from the SPT- $N$ value and effective overburden stress $\sigma_{\mathrm{v} 0}^{\prime}$ by Eq. $(2)^{2}$. 


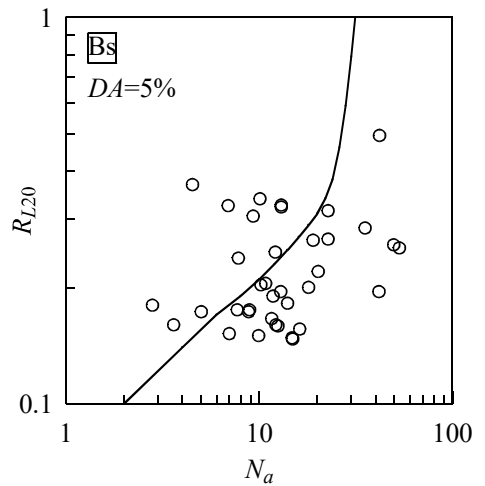

(a) $\mathrm{Bs}$

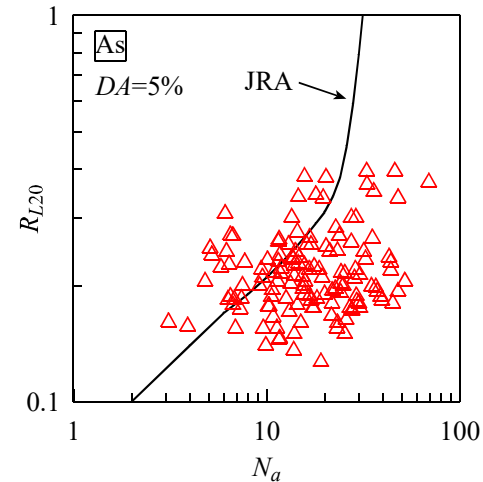

(b) As

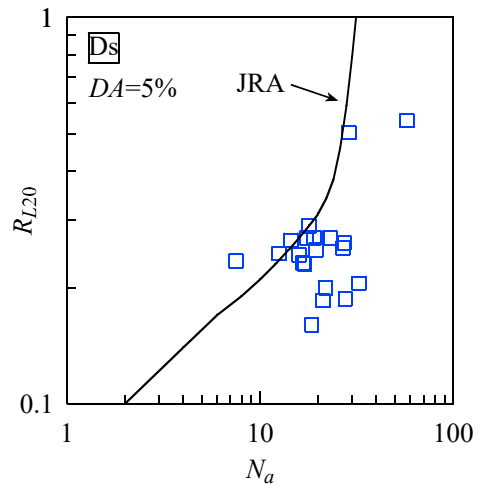

(c) Ds

Figure 2. Relationships between $R_{\mathrm{L} 20}$ and corrected SPT- $N$ value in each geological age

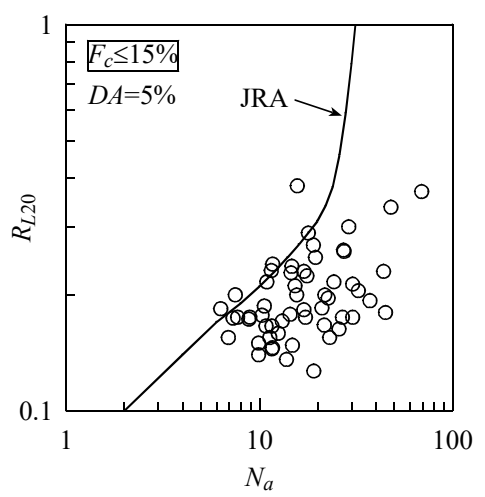

(a) $F_{\mathrm{c}} \leq 15 \%$

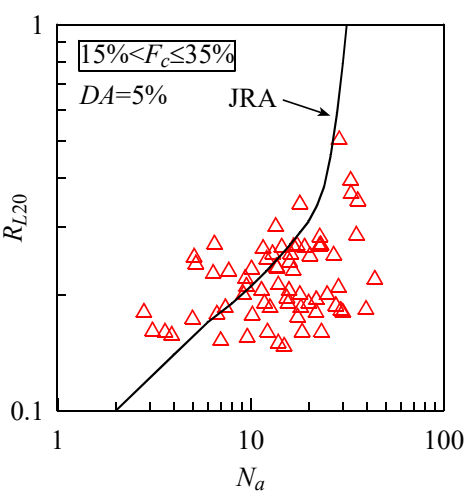

(b) $15 \%<F_{\mathrm{c}} \leq 35 \%$

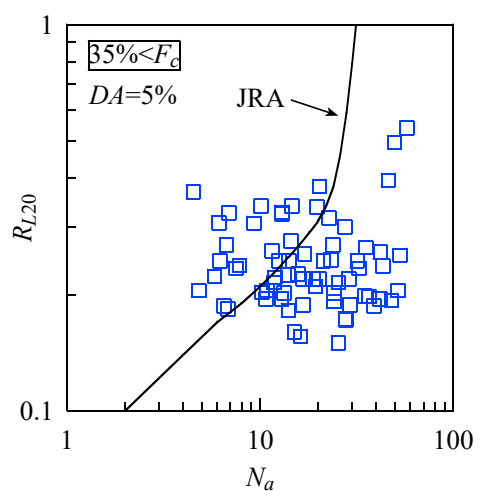

(c) $35 \%<F_{\mathrm{c}}$

Figure 3. Relationships between $R_{\mathrm{L} 20}$ and corrected SPT- $N$ value classified by fines content

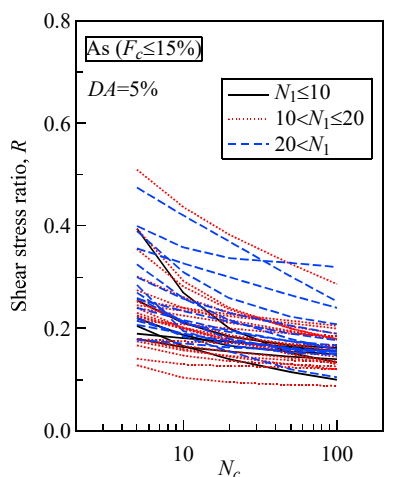

(a) As $\left(F_{\mathrm{c}} \leq 15 \%\right)$

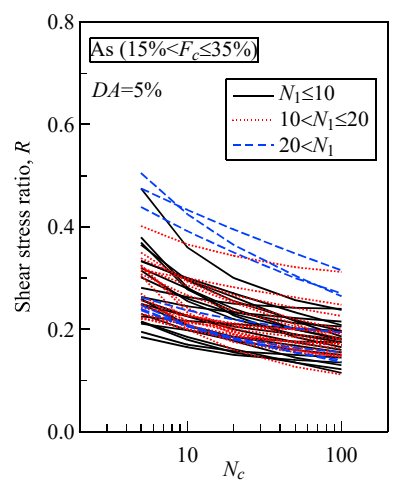

(b) As $\left(15 \%<F_{\mathrm{c}} \leq 35 \%\right)$

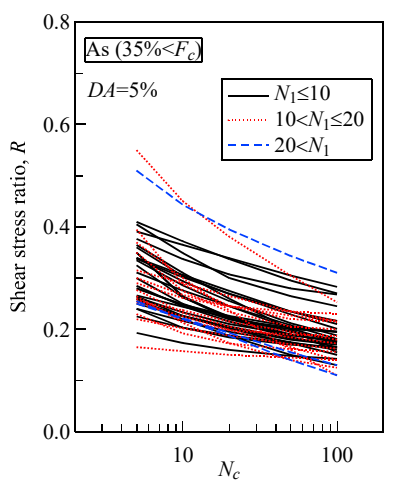

(c) As $\left(35 \%<F_{\mathrm{c}}\right)$

Figure 4 Liquefaction strengths of As sands

$$
N_{1}=\frac{170 N}{\sigma_{v 0}^{\prime}+70} \quad\left(\sigma_{v 0}^{\prime} \text { in } \mathrm{kPa}\right)
$$

It is seen from Figure 4 that liquefaction strength curves have a tendency to locate higher as fines content increases or $N_{1}$ value is larger. It is, however, also seen that data scatters significantly. This 
fact suggests difficulty to formulate $R-N_{\mathrm{c}}$ relationships directly. On the other hand, relationships between $R_{L 5}$ and $R_{L 20}$, and between $R_{L 100}$ and $R_{L 20}$ are less scatter regardless of $N_{1}$ value as shown in Figure 5 to Figure 8. This indicates shapes of the liquefaction strength curves are similar to each other. The relationships between $R_{\mathrm{L} 5}$ and $R_{\mathrm{L} 20}$ are shown in Figure 5 by classifying the geological age. Linear sold line in the figure is a recurrent equation obtained by a least square method. Power of the recurrent equation for Ds is somewhat different from those for Bs and As. The same characteristics are also seen in $R_{\mathrm{L} 100}-R_{\mathrm{L} 20}$ relationships. On the other hand, slope of the recurrent curve on $R_{\mathrm{L} 100}-R_{\mathrm{L} 20}$ relationships in Figure 8 shows different slope between the case with $F_{\mathrm{c}} \leq 15 \%$ and with $15 \%<F_{\mathrm{c}}$. This tendency is not clear for $R_{\mathrm{L} 5}-R_{\mathrm{L} 20}$ relationships in Figure 7.

Above discussion indicates that the relationships between $R_{\mathrm{L} 5}$ and $R_{\mathrm{L} 20}$, and between $R_{\mathrm{L} 100}$ and $R_{\mathrm{L} 20}$ can be classified as follows. When focusing on the geological age, they can be classified into two categories, i.e., a pair of fill and Holocene sand (referred as Bs + As in the followings) and Pleistocene sand, Ds. When focusing on fines contents, they also can be classified into two categories, i.e., sand with $F_{\mathrm{c}} \leq 15 \%$ and with $15 \%<F_{\mathrm{c}}$. Therefore, in total soil can be classified into four categories. However, classifying into four categories may not be relevant because number of data sets of a classification is too small to make statistical treatment. In addition a grain size analysis is not the test that always carried out, and it is known that there are many errors if fines content is estimated only from the soil name in the borehole data. Moreover, there are not significant differences between empirical equations for fines contents. Considering these, we propose the empirical equations that focus only for the geological age, i.e., Bs+As and Ds. Obtained empirical relationships are summarized in Figure 9 and Figure 10, and in Table3.

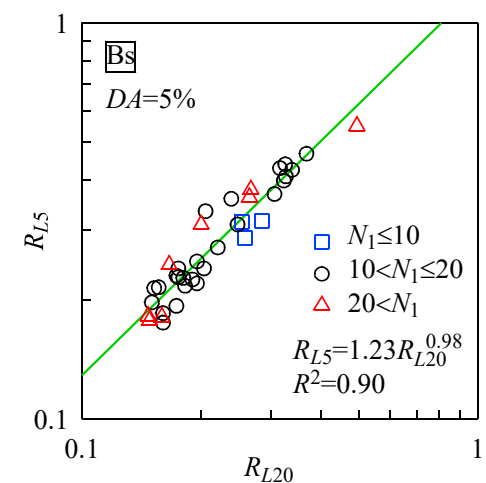

(a) $\mathrm{Bs}$

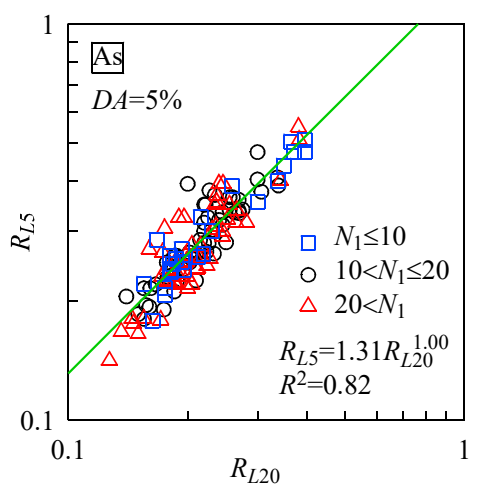

(b) As

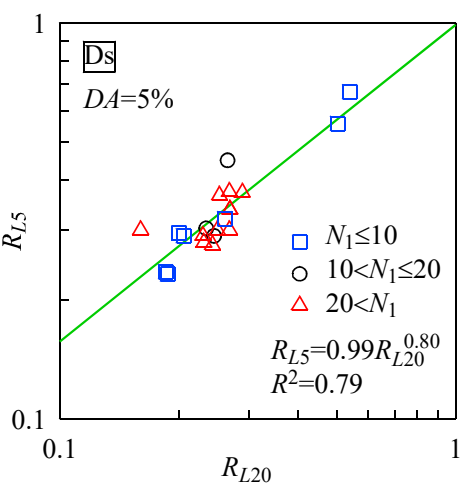

(c) Ds

Figure $5 R_{\text {L5 }}$ vs. $R_{\text {L20 }}$ relationships in each geological age

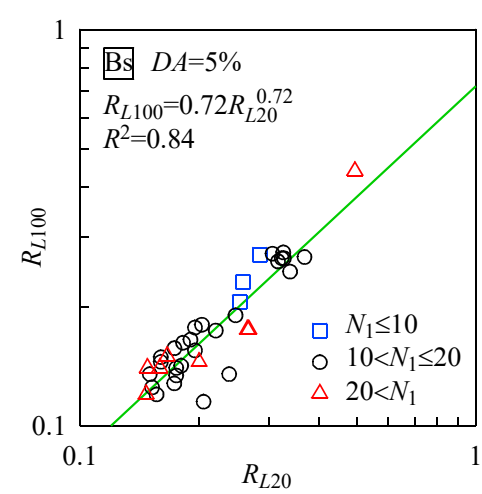

(a) $\mathrm{Bs}$

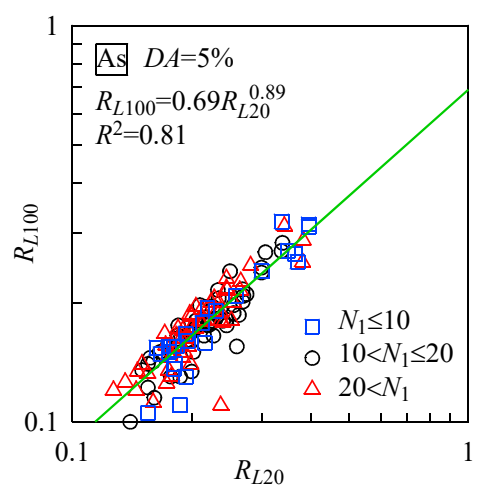

(b) As

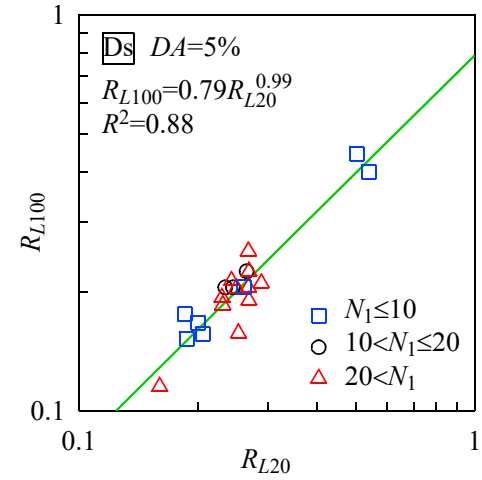

(c) Ds

Figure $6 R_{\mathrm{Lq} 00}$ vs. $R_{\mathrm{L} 20}$ relationships in each geological age 


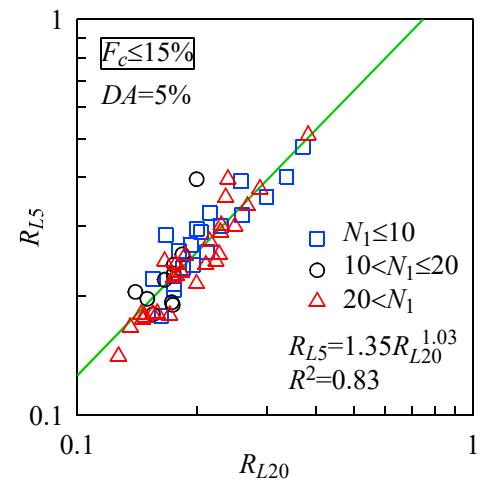

(a) $F_{\mathrm{c}} \leq 15 \%$

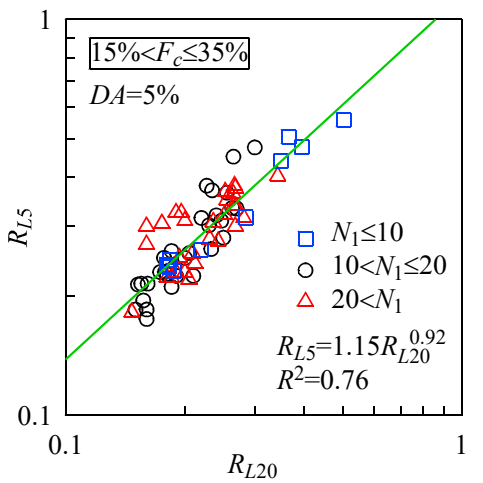

(b) $15 \%<F_{\mathrm{c}} \leq 35 \%$

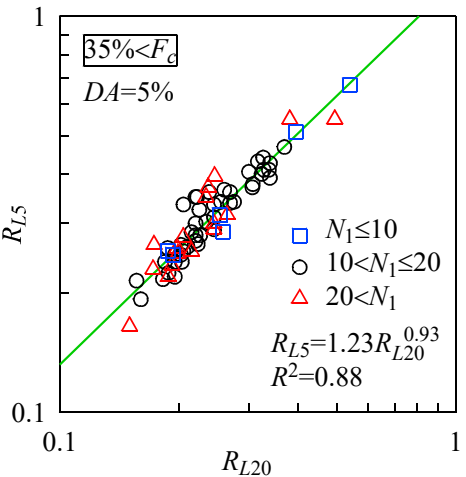

(c) $35 \%<F_{\mathrm{c}}$

Figure $7 R_{\mathrm{L} 5}$ vs. $R_{\mathrm{L} 20}$ relationships classified by $F_{c}$

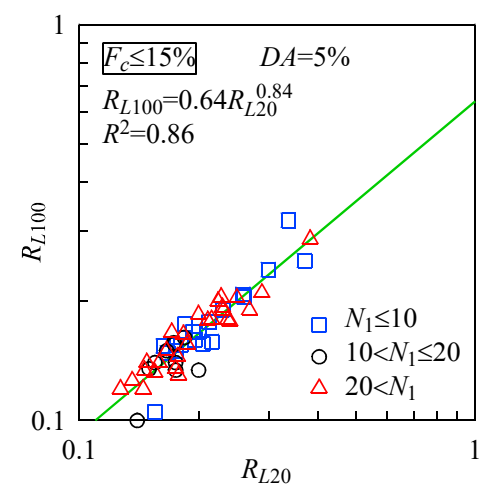

(a) $\quad F_{\mathrm{c}} \leq 15 \%$

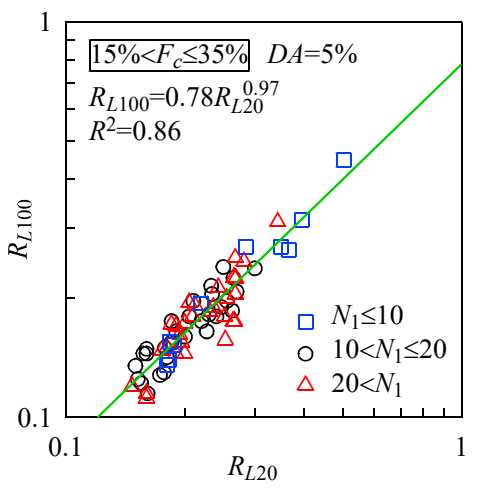

(b) $15 \%<F_{\mathrm{c}} \leq 35 \%$

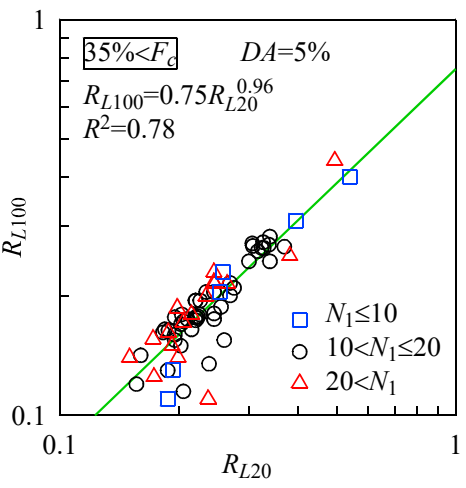

(c) $35 \%<F_{\mathrm{c}}$

Figure $8 R_{\mathrm{L} 100}$ vs. $R_{\mathrm{L} 20}$ relationships classified by $F_{c}$

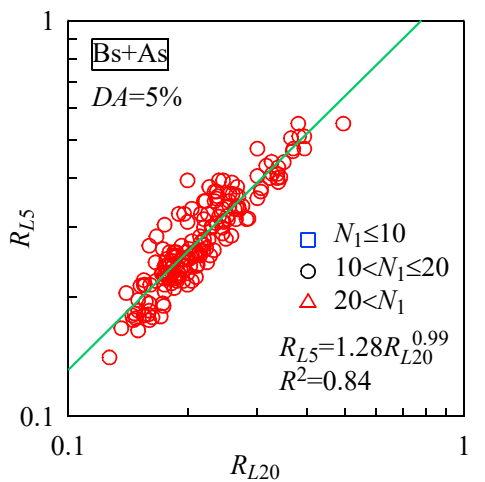

(a) $\mathrm{Bs}+\mathrm{As}$

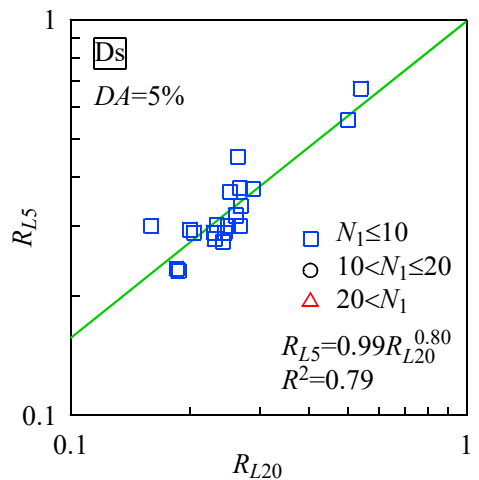

(b) Ds

Figure 9 Empirical $R_{\mathrm{L} 5} R_{\mathrm{L} 20}$ relationships

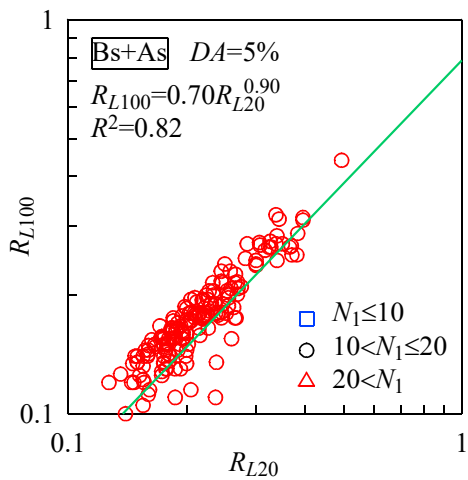

(a) $\mathrm{Bs}+\mathrm{As}$

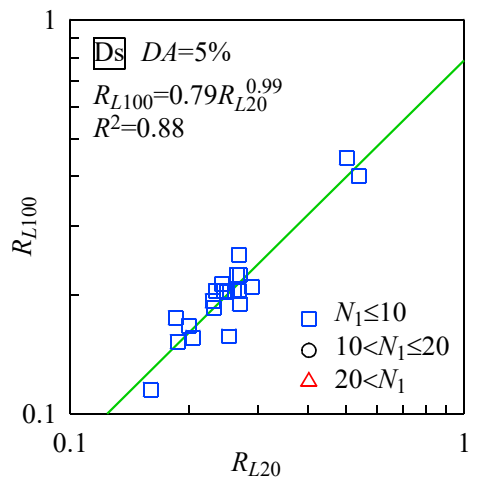

(b) Ds

Figure 10 Empirical $R_{\mathrm{L} 100}-R_{\mathrm{L} 20}$ relationships 
Table3 Summary of empirical equations

\begin{tabular}{c|c|c}
\hline & $\mathrm{Bs}+\mathrm{As}$ & $\mathrm{Ds}$ \\
\hline \hline$R_{\mathrm{L} 5}-R_{\mathrm{L} 20}$ relationships & $R_{\mathrm{L} 5}=1.28 R_{\mathrm{L} 20}^{0.99}$ & $R_{\mathrm{L} 5}=0.99 R_{\mathrm{L} 20}{ }^{0.80}$ \\
\hline $\begin{array}{c}R_{\mathrm{L} 100}-R_{\mathrm{L} 20} \\
\text { relationships }\end{array}$ & $R_{\mathrm{L} 100}=0.70 R_{\mathrm{L} 20}^{0.90}$ & $R_{\mathrm{L} 100}=0.79 R_{\mathrm{L} 20}^{0.99}$ \\
\hline
\end{tabular}

\section{INTERPOLATION OF LIQUEFACTION STRENGTH CURVE}

Liquefaction strengths at number of cycles $N_{c}=5,20$, and 100 are discussed in the preceding. Therefore, the result is given by three points in $R-N_{c}$ plane. In the engineering practice, however, it is more convenient to express the relationships as continuous functions. In this research, liquefaction strength curve that passes these three points is expressed as

$$
R=\frac{a}{\log N_{\mathrm{c}}-b}+c
$$

where $a, b$, and $c$ are parameters, and can be calculated as

$$
b=\frac{1.693 k-1.204}{1.301 k-0.602}, a=\frac{R_{\mathrm{L} 5}-R_{\mathrm{L} 20}}{\frac{1}{0.699-b}-\frac{1}{1.301-b}}, c=R_{\mathrm{L} 20}-\frac{a}{1.301-b}
$$

It is noted that $N_{c}$ is fixed to be either 5,20 , or 100 in Eq. (4), and $k=\left(R_{\mathrm{L} 5}-R_{\mathrm{L} 20}\right) /\left(R_{\mathrm{L} 5}-R_{\mathrm{L} 100}\right)$. Coefficients $a, b$, and $c$ are obtained sequentially from Eq. (4).

An example is shown in Figure 11 for the geological age $\mathrm{Bs}+\mathrm{As}$ and $R_{\mathrm{L} 20}=0.200$. Liquefaction strengths are obtained from Table3, which result in $R_{\mathrm{L} 5}=0.260$ and $R_{\mathrm{L} 100}=0.164$. Then $b=0.6487$, $a=0.2625$, and $c=0.0653$ are obtained from Eq. (4). The solid red line in Figure 11 is obtained from Eq. (3). Some test data with liquefaction strength $R_{\mathrm{L} 20}=0.195 \sim 0.204$ are also shown in the figure and proposed equation is shown to agree with test results.

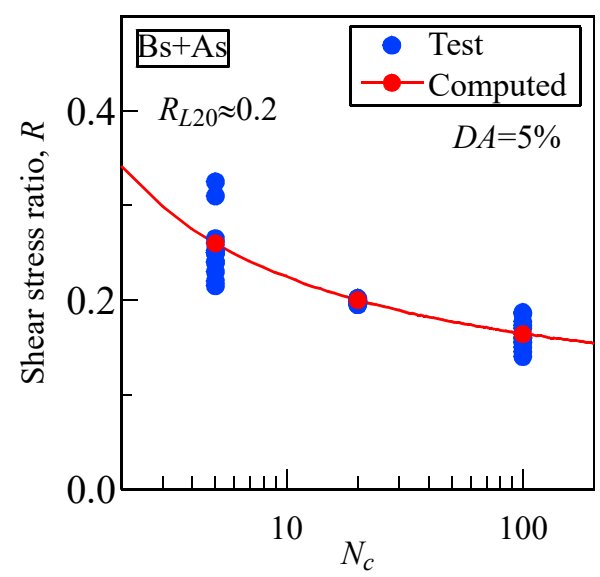

Figure 11 Example of comparison of liquefaction strength curve 
As Eq. (3) is developed by using the data at $N_{c}=5,20$, and 100, it is applicable between $N_{c}=5$ and $N_{c}=100$ or a little wider. It is noted that Eq. (3) is just a mathematical equation. When looking at the equation, for example, $c$ corresponds to minimum liquefaction strength and $b$ corresponds to $N_{c}$ at which liquefaction strength becomes infinite, but these parameters do not have these physical meanings. Equation (3) is convenient for calculating liquefaction strength at $N_{c}$ that is not used in this research. For example, liquefaction strength at $N_{c}=15$ defined in the AIJ design specification ${ }^{1)}$ can be easily calculated.

\section{CONCLUSION}

Empirical relationships for the liquefaction strength in wide range of number of cycles causing liquefaction are proposed. They have advantage to be applied in variety of material because they are developed by using about 200 test results on undisturbed samples. Result of this research is summarized as follows;

1) Liquefaction strengths and liquefaction strength curves scatters significantly, but shapes of the liquefaction strength curve are similar to each other.

2) Relationships between liquefaction strength and number of cycles causing liquefaction, $N_{\mathrm{c}}=5,20$ and100 were classified based on geological ages (Bs+As and Ds) and based on fines contents $F_{c}$ $\left(F_{\mathrm{c}} \leq 15 \%\right.$ and $\left.15 \%<F_{\mathrm{c}}\right)$, but only classification based on geological ages are employed considering the convenience in the engineering practice.

3) An interpolation function is proposed to obtain continuous liquefaction strength curve. This equation is applicable in wide range of number of cycles causing liquefaction from 5 to 100 .

\section{REFERENCES}

1) Architectural Institute of Japan: Recommendations for design of building foundations, 2001 Revision, Maruzen, 2001, 486pp. (in Japanese)

2) Japan Road Association: Specifications for Highway Bridges, Part V (Seismic design), Maruzen, 2012, 318pp. (in Japanese)

3) Tatsuoka, F., Yasuda, S., Iwasaki, T. and Tokida, K.: Normalized dynamic undrained strength of sands subjected to cyclic and random loading, Soils and Foundations, Vol. 20, No.3, 1980, pp. $1-16$.

4) Kokusho, T., Shimada, M. and Kato, S.: Characteristics of dense sand cyclic sheared under undrained condition, Proc., The 16h Japan National Conference of Soil Mechanics and Foundation Engineering, 1981, pp. 609-612

5) Azuma, T., Otsuka, H. and Ninomiya, Y.: Formulation of liquefaction strength curve considering relative density of sandy soil, Proc., 49th Annual Conf. of the Japan Society of Civil Engineering, Vol. III, 1994, pp. 528-529 (in Japanese)

6) Yasu, H., Uchida, A., Taya, Y. and Hatanaka, M.: Modeling of liquefaction strength curves for undrained sandy soils, Summaries of the Technical Papers of Annual Meeting of AIJ (Hokuriku), Vol. B1, 2002, pp. 419-420 (in Japanese)

7) Yoshida, N., Ohya, Y., Sawada, S. and Nakamura, S.: Simplified procedure for evaluating liquefaction potential under ocean trench type long period earthquake, Journal of JAEE, Vol.9, No. 3, 2009, pp. 28-47

8) Mikami, T. and Yoshida, N.: Grouping and empirical equation of liquefaction strength curve, Proc., Proc., 65th Annual Conf. of the Japan Society of Civil Engineering, Vol. 3, 2010, pp. 683-684 (in Japanese)

9) Mikami, T., Yoshida, N. and Harada, K.: Typification of liquefaction strength curve and proposal of curve, Proc., 66th Annual Conf. of the Japan Society of Civil Engineering, Vol. 3, 2014, pp. 61-62 (in Japanese) 
10) Towhata, I., Taguchi, Y. and Murata, T.: Evaluation of liquefaction judgement method, Kisoko, Vol.41, No.4, 2013, pp.13-16 (in Japanese)

11)Matsuo, O. and Azuma, T.: Assessment of liquefaction potential, Civil Engineering Journal, PWRI, Vol. 39, No. 2, 1997, pp. 20-25 (in Japanese)

12) JGS Committee on laboratory test standard: Japanese standards and explanations of laboratory tests of geomaterials, Japanese Geotechnical Society, 2010, 1156pp.

(Original Japanese Paper Published: January, 2016)

(English Version Submitted: July 14, 2016)

(English Version Accepted: July 20, 2016) 